\title{
Scaling Relations on Basal Plane Vacancies of Transition Metal Dichalcogenides for CO2 Reduction
}

\author{
Ji, Yongfei; Nørskov, Jens K.; Chan, Karen
}

Published in:

Journal of Physical Chemistry C

Link to article, DOI:

10.1021/acs.jpcc.8b11628

Publication date:

2019

Document Version

Peer reviewed version

Link back to DTU Orbit

Citation (APA):

Ji, Y., Nørskov, J. K., \& Chan, K. (2019). Scaling Relations on Basal Plane Vacancies of Transition Metal Dichalcogenides for $\mathrm{CO}_{2}$ Reduction. Journal of Physical Chemistry C, 123(7), 4256-4261.

https://doi.org/10.1021/acs.jpcc.8b11628

\section{General rights}

Copyright and moral rights for the publications made accessible in the public portal are retained by the authors and/or other copyright owners and it is a condition of accessing publications that users recognise and abide by the legal requirements associated with these rights.

- Users may download and print one copy of any publication from the public portal for the purpose of private study or research.

- You may not further distribute the material or use it for any profit-making activity or commercial gain

- You may freely distribute the URL identifying the publication in the public portal

If you believe that this document breaches copyright please contact us providing details, and we will remove access to the work immediately and investigate your claim 


\section{Scaling relations on Basal Plane Vacancies of}

\section{Transition Metal Dichalcogenides for $\mathrm{CO}_{2}$}

\section{Reduction}

Yongfei Jiłt\%, Jens K. Nфrskov \#, Karen Chan\#*

¡SUNCAT Center for Interface Science and Catalysis, SLAC National Accelerator Laboratory, 2575 Sand Hill Road, Menlo Park, California 94025, USA.

¿SUNCAT Center for Interface Science and Catalysis, Department of Chemical Engineering, Stanford University, Stanford, California 94305, USA.

\% Department of Chemistry and Chemical Engineering, Guangzhou University, 230 Wai Huan Xi Road,Guangzhou Higher Education Mega Center, Guangzhou, 510006, P. R. China

\#Catalysis Theory Center, Department of Physics, Technical University of Denmark, Lyngby, Denmark 2820

ABSTRACT. Transition metal dichalcogenides (TMDs) have shown promising electrocatalytic performance for $\mathrm{CO}_{2}$ reduction $\left(\mathrm{CO}_{2} \mathrm{R}\right)$ recently. However, the development of efficient and selective catalysts remains a major challenge. While recent studies have suggested the importance of activation energies as activity descriptors for $\mathrm{CO}_{2} \mathrm{R}$ beyond $\mathrm{CO}$, the scaling of intermediate binding energies present a first step in computational catalyst screening. Here, we investigate the 
basal vacancy on $2 \mathrm{H}$ and $1 \mathrm{~T} / 1 \mathrm{~T}$ ' phase group $\mathrm{V}$, VI and $\mathrm{X}$ TMDs for $\mathrm{CO}_{2}$ reduction. We find that the change of oxophicility and carbophilicity on each group of TMDs follow different trends, which leads to different scaling relations amongst key intermediates. Our thermochemical analysis also suggests Group V and VI TMDs to be either selective for hydrogen evolution reaction (HER) or prone to $\mathrm{OH}$ poisoning. However, the initial analysis suggests group $\mathrm{X}$ TMDs to be possible candidates for active and selective $\mathrm{CO}_{2}$ reduction without suffering from $\mathrm{OH}$ poisoning, which motivates further theoretical kinetic studies. We furthermore find that their reaction energetics can be tuned by the density of the basal vacancies.

\section{Introduction}

Electrochemical reduction of $\mathrm{CO}_{2}$ to value-added organic molecules has attracted intensive attention as a potential way to mitigate the energy and environmental crisis. Recently, transition metal dichalcogenides (TMDs) have been suggested to be electrochemically active for $\mathrm{CO}_{2}$ reduction $\left(\mathrm{CO}_{2} \mathrm{RR}\right)_{1-4}$. Asadi et al. reported $\mathrm{CO}_{2}$ to $\mathrm{CO}$ on group VI TM sulfides and selenides with a selectivity of $24 \%$ at a low overpotential of 54 millivolts 1 ; Liu et al. found that MoTe2 can electrochemically reduce $\mathrm{CO}_{2}$ to $\mathrm{CH}_{4}$ with a selectivity of $84 \%$ at -1.0 VRHE at relatively high current density3; Xu et al. found that the selectivity can be tuned by alloying Se with $\mathrm{MoS}_{2}$ to form MoSSe, which can boost the reduction of $\mathrm{CO}_{2}$ to syngas4. The active sites of TMDs have been suggested to be the edge sites2,5 which can be easily doped with transition metals 1,4. Abbasi et al. found that $\mathrm{Nb}$ doped $\mathrm{MoS}_{2}$ can promote $\mathrm{CO}_{2}$ reduction to $\mathrm{CO}$ whereas the Ta doping shows negative effects6. To suppress hydrogen evolution (HER), all these measurements were conducted in 1-ethyl-3-methylimidazolium tetrafluoroborate (EMIM-BF4), which has been suggested to bind $\mathrm{CO}_{2}$ and lower the overpotential7 for $\mathrm{CO}_{2} \mathrm{RR}$, to exert a field-induced stabilization of the 
intermediates 8 or to provide a source of protons for transfer9. On the other hand, EMIM+ cations have been shown to degrade under the reaction condition which can affect the measured $\mathrm{CO}_{2} \mathrm{RR}$ product distribution and therefore necessitates the use of isotope labelling.10

To deconvolute the effect of the ionic liquid from the intrinsic activity of these catalysts, a combined experimental and theoretical study in aqueous condition 11 on nine TM phosphides and five TMDs was performed. In all the ionic compounds considered, the predominant product was found to be $\mathrm{H}_{2}$. The selectivity towards $\mathrm{H}_{2}$ was investigated computationally and found to either arise from low thermodynamic limiting potentials for HER relative to $\mathrm{CO}_{2} \mathrm{RR}$ or, in the case of the TMDs, to arise from poor scaling of the critical H-CO transition state from proton-electron transfer to $\mathrm{CO}$.

The activity of the basal planes of TMDs has, to date, been unexplored for its potential for $\mathrm{CO}_{2} \mathrm{RR}$. Although the density of sites on the basal plane are high, there are generally inert. However, Tsai et al. showed that the basal plane of TMDs can be activated for HER by creating chalcogen vacancies12,13, and the binding energy of the intermediates can be tuned by the density of the chalcogen vacancy and in-plane strain which change the number of gap states and density of states near fermi level. This presents a potential method for tuning the activity and selectivity of TMDs for $\mathrm{CO}_{2} \mathrm{RR}$. On the other hand, because the vacancy of the TMDs expose three lowcoordinated TM atoms, the interaction with the adsorbates may differ from those at the edge sites and result in new scaling relations amongst binding energies. Currently, only the basal plane vacancies of group VI TMDs in the $2 \mathrm{H}$ phase (figure 1) have been investigated for HER.

In this work, we perform an initial thermochemical screening of the $2 \mathrm{H}$ and $1 \mathrm{~T} / 1 \mathrm{~T}$ ' (figure 1) sulfides and selenides for $\mathrm{CO}_{2} \mathrm{RR}$. We consider group $\mathrm{V}$ and VI sulfides in the $2 \mathrm{H}$ phase, and 
group V, VI, and $\mathrm{X}$ in the $1 \mathrm{~T}$ phase, since group $\mathrm{X}$ TMDs only exist in $1 \mathrm{~T}$ phase. As in our previous works 14,15, we will focus on the scaling relations between the formation energies of the intermediates $\left(\mathrm{E}\left(\mathrm{COOH}^{*}\right), \mathrm{E}\left(\mathrm{CHO}^{*}\right)\right.$ and $\left.\mathrm{E}(\mathrm{CO} *)\right)$ in the first three key steps for $\mathrm{CO}_{2}$ reduction (reaction (1-3)).

$$
\begin{aligned}
& \mathrm{CO}_{2}+\mathrm{H}^{+}+\mathrm{e}^{-}+* \rightarrow \mathrm{COOH}^{*} \\
& \mathrm{COOH}^{*}+\mathrm{H}^{+}+\mathrm{e}^{-} \rightarrow \mathrm{CO}^{*}+\mathrm{H}_{2} \mathrm{O} \\
& \mathrm{CO}^{*}+\mathrm{H}^{+}+\mathrm{e}^{-} \rightarrow \mathrm{CHO}^{*}
\end{aligned}
$$

We find that the scaling relations on TMDs are different from those on pure TMs and the oxygen and carbon affinity play important role in forming different scaling relation among different group TMDs. We also evaluate the thermochemistry for the competitive hydrogen evolution reaction (HER) and the propensity for $\mathrm{OH}$ poisoning (See Supporting Information). Overall, the thermochemical analysis suggests group X TMDs to be potential candidates for efficient $\mathrm{CO}_{2}$ reduction with high selectivity and resistance to $\mathrm{OH}$ poisoning, which motivates further detailed theoretical studies of their corresponding kinetic barriers. Furthermore, we found that the electrocatalytic performance can be tuned by increasing the density of basal vacancies.

\section{Theoretical Methods}

All calculations were carried out using density functional theory implemented in Quantum Espresso with periodic boundary conditions16, using plane-wave basis sets17 and ultrasoft pseudopotentials18, interfaced with the Atomic Simulation Environment19. The Bayesian error estimation exchange-correlation functional with van der Waals interactions (BEEF-vdW)20, which is optimized for chemisorption energies and van der Waals interactions, was used with a plane- 
wave cutoff of $500 \mathrm{eV}$ and a density cutoff of $5000 \mathrm{eV}$. A rectangular (4x4) supercell with a vacuum of $11 \AA$ was used for calculation. The Brillouin zone was sampled with a $(2 \times 2 \times 1)$ Monkhorst-pack grid K-points. All atoms were relaxed until the maximum force on the atoms is smaller than $0.05 \mathrm{eV} / \AA$. A dipole correction in the $\mathrm{z}$ direction was used 21 . The computational hydrogen electrode 22 was used to calculate the free energy of formation of the intermediates as in previous works 14,15. Solvent stabilizations of $0.25 \mathrm{eV}, 0.1 \mathrm{eV}, 0.1 \mathrm{eV}$ and $0.25 \mathrm{eV}$ were applied to the binding energies of $\mathrm{COOH}^{*}, \mathrm{CO}^{*}, \mathrm{CHO}^{*}$ and $\mathrm{OH}^{*}$ respectively23.

Fig. 1 shows the structure of the TMDs in both the $2 \mathrm{H}$ and $1 \mathrm{~T}$ phases. In both cases, the metal atoms are six-fold coordinated to the chalcogens. The difference between the two phases is that the chalcogens are coordinated in a trigonal prismatic arrangement in the $2 \mathrm{H}$ phase and in an octahedral arrangement in the $1 \mathrm{~T}$ phase. In our investigations of the effect of defect densities on group X TMD in the $1 \mathrm{~T}$ phase (cf. Fig. 5), vacancies were removed following the order of the number shown in the top schematic of the 1T phase.

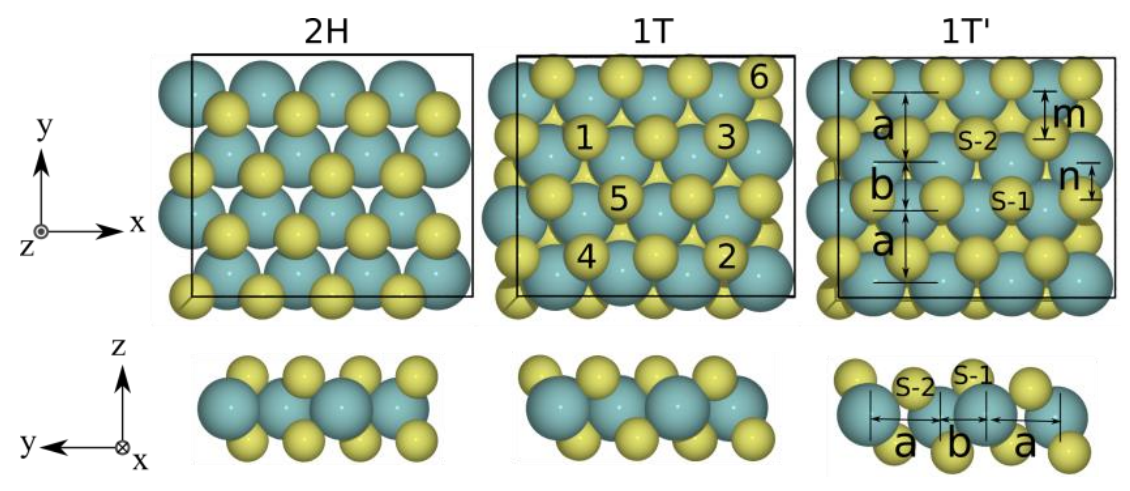

Figure 1. Structures of single layer transition metal dichalchogenides in $2 \mathrm{H}, 1 \mathrm{~T}$ and $1 \mathrm{~T}$ ' phase. Green and yellow spheres stand for metal and chalcogen atoms. In our investigations of the effect of defect densities on group X TMD (cf. Fig. 5), vacancies were removed following the order of the number shown in the middle figure. 
The group VI TMDs in the $1 \mathrm{~T}$ phase undergoes a $(1 \mathrm{x} 2)$ reconstruction spontaneously to the $1 \mathrm{~T}^{\prime}$ phase. In this phase, the vertical distances between the rows of the transition metals alternates between "a" and "b" as illustrated in Fig .124,25. This reconstruction creates two inequivalent chalcogen vacancies marked S-1 and S-2 in Figure 1. Table S1 summarizes the formation energies of the S-1 and S-2 vacancies on the group VI TMDs in the 1T'-phase. Removing S-2 is always more facile, as it has larger bond distances to the coordinating transition metal atoms than S-1, as illustrated in Fig. 1 (distance $m>$ distance $n$ ). Thus, we only consider the adsorption of the intermediates at the S-2 vacancy. We have considered various binding configurations of the intermediates, and explore the scaling relations determined from the most stable ones.

\section{Results and Discussion}

\section{Scaling Relations}

Figure 2(a) shows the scaling relations and the most stable structures of the intermediates $\mathrm{COOH}^{*}$, $\mathrm{CO}^{*}$, and $\mathrm{CHO}^{*}$ adsorbed on the vacancy of all the TMDs $\left(\mathrm{OH}^{*}\right.$ and $\mathrm{H}^{*}$ are shown in Figure $\left.\mathrm{S} 1\right)$. Because the adsorbates bind with similar configurations within the same group of TMDs, the structures for each group are exemplified by one compound: group V by VS2, group VI by $\mathrm{MoS}_{2}$ and group $\mathrm{X}$ by $\mathrm{PtS}_{2}$. ${ }^{*} \mathrm{COOH}$ adsorbs on the $2 \mathrm{H}-\mathrm{VI}$ and $1 \mathrm{~T}-\mathrm{X}$ TMDs in a top-bridge (C atop, $\mathrm{O}$ on bridge) geometry, but on other TMDs in a top-top ( $\mathrm{C}$ atop, $\mathrm{O}$ atop) geometry; $\mathrm{CO}^{*}$ adsorbs on 2H-VI TMDs at the hollow site, on 1T-X TMDs at the bridge site and on other TMDs at the top site; $\mathrm{CHO}^{*}$ adsorbs on the $2 \mathrm{H}-\mathrm{VI}$ and TMDs with a bridge-top ( $\mathrm{C}$ on bridge, $\mathrm{O}$ atop) geometry, but on the 1T'-VI TMDs in the top-bridge ( $\mathrm{C}$ atop, $\mathrm{O}$ on bridge) configuration, and on other TMDs with a top-top geometry. $\mathrm{E}\left(\mathrm{COOH}^{*}\right)$ and $\mathrm{E}\left(\mathrm{CHO}^{*}\right)$ are known to scale well with $\mathrm{E}(\mathrm{CO} *)$ on $\mathrm{TM}$ 
surfaces. In contrast, Figures 2(b) and (c) show that TMDs show significant differences in scaling amongst the different groups and phases. These differences do not arise solely from differences in the adsorption structures of the intermediates. For example, the $2 \mathrm{H}-\mathrm{V}, 1 \mathrm{~T}-\mathrm{V}$ and 1T-VI' TMDs show similar binding configurations for $\mathrm{COOH}^{*}$ and $\mathrm{CO}^{*}$, but very different scaling lines. 
Similarly, 2H-V and 1T-V TMDs show similar binding configurations for $\mathrm{CHO}^{*}$ and $\mathrm{CO}^{*}$ but again different scaling lines.
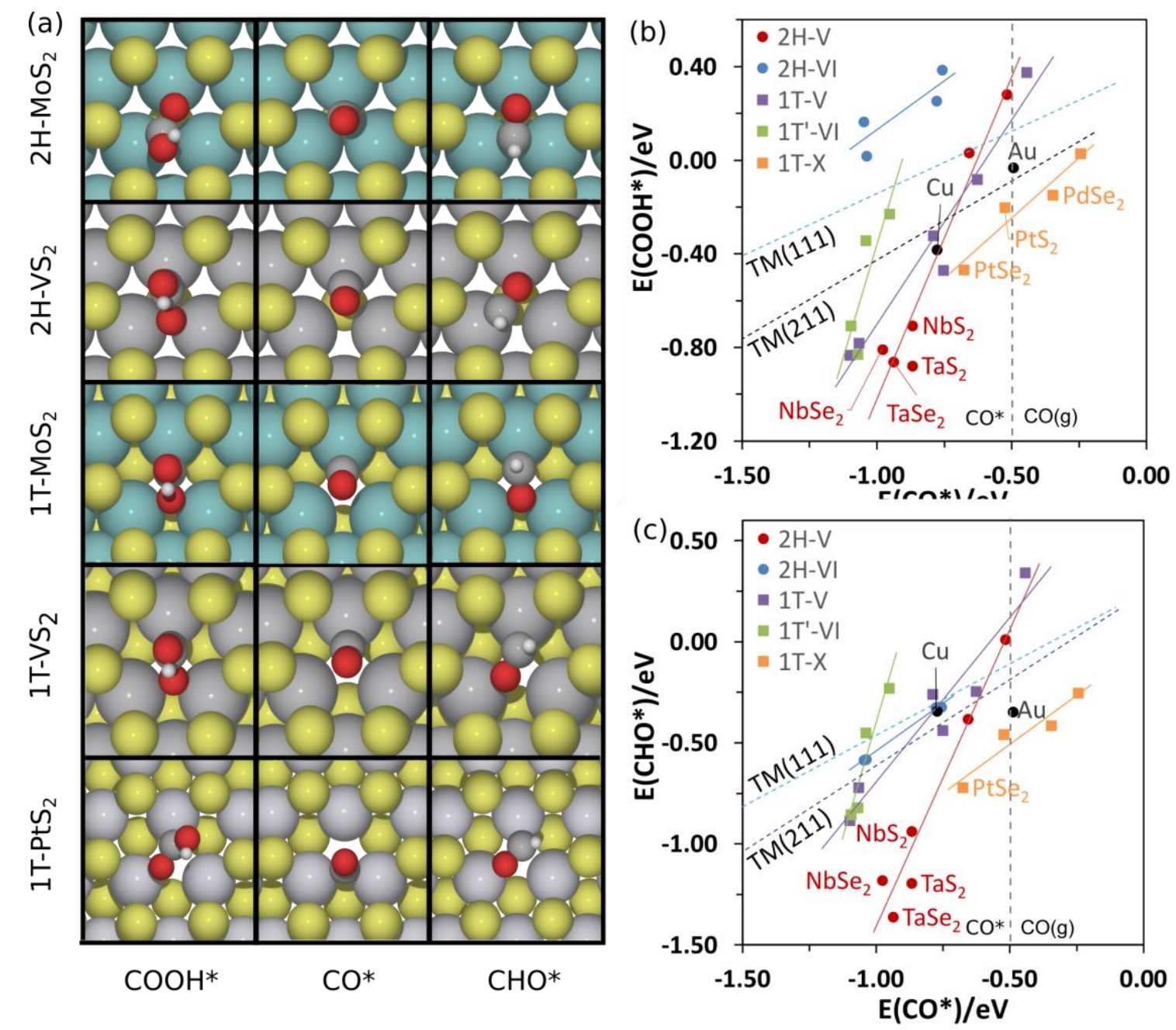

Figure 2, (a) Adsorption structures of the intermediates; scaling relation of $\mathrm{E}\left(\mathrm{COOH}{ }^{*}\right)$ and $\mathrm{E}\left(\mathrm{CHO}^{*}\right)$ with $\mathrm{E}\left(\mathrm{CO}^{*}\right)$. For clarity, only part of the data points are labeled in (b) and (c), figures with full labels can be found in Figure S2. The vertical dashed lines indicate the E $\left(\mathrm{CO}^{*}\right)$ at which an isolated ${ }^{*} \mathrm{CO}$ is in equilibrium with 0.01 bar gaseous $\mathrm{CO}$. The catalysts to the right of the line tend to bind $\mathrm{CO}$ weakly and are expected to be selective for $\mathrm{CO}$ production. The catalysts to the left may able to further reduce $\mathrm{CO}^{*}$.

The differences in the oxophilicity of the different groups and phases, on the other hand, can be shown to contribute to the differences amongst the scaling lines. Since the $\mathrm{COOH}^{*}$ are bonded 
to the $\mathrm{TM}$ atoms via the $\mathrm{C}$ and $\mathrm{O}$ atoms, $\mathrm{E}\left(\mathrm{COOH}^{*}\right)$ scales with the binding energies of $\mathrm{C}$ - and $\mathrm{O}$ bound species, for example $\mathrm{CO}^{*}$ and $\mathrm{OH}^{*}$ :

$$
E\left(\mathrm{COOH}^{*}\right)=\alpha E\left(\mathrm{CO}^{*}\right)+\beta E\left(O H^{*}\right)+\gamma
$$

For $\mathrm{E}\left(\mathrm{COOH}^{*}\right)$ and $\mathrm{E}\left(\mathrm{CHO}^{*}\right)$ to scale with $\mathrm{E}(\mathrm{CO} *), \mathrm{E}\left(\mathrm{OH}^{*}\right)$ must scale with $\mathrm{E}\left(\mathrm{CO}^{*}\right)$ as well:

$$
\begin{aligned}
& E\left(C O^{*}\right)=\kappa E\left(O H^{*}\right)+\lambda \\
& E\left(C O O H^{*}\right)=(\alpha+\kappa \beta) E\left(C O^{*}\right)+\gamma^{\prime}
\end{aligned}
$$

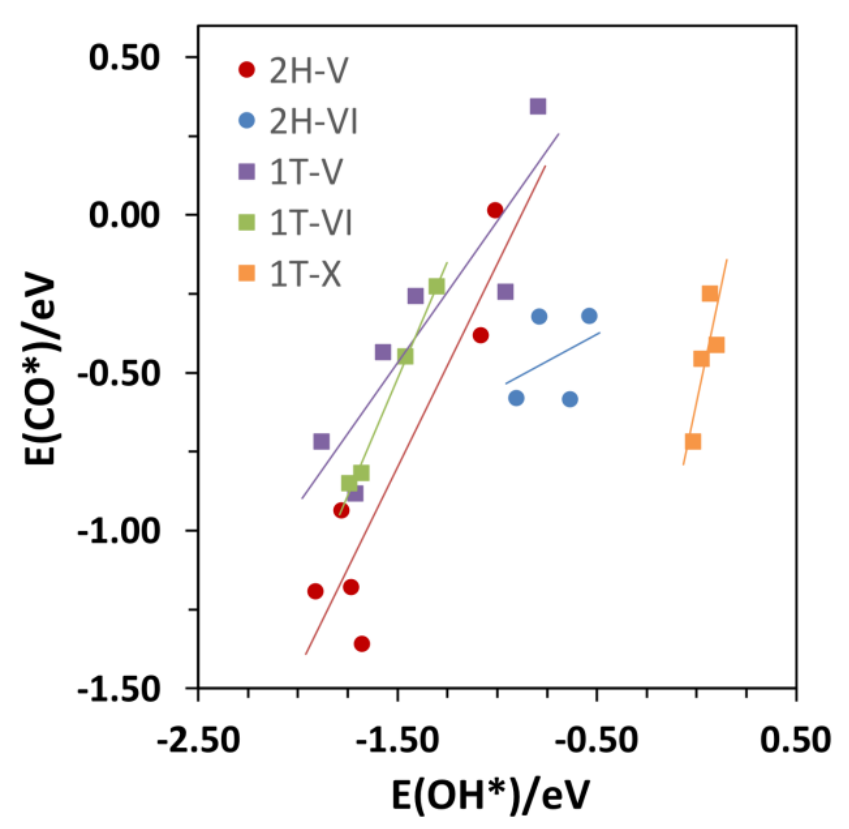

Figure 3. Scaling relation between $\mathrm{E}\left(\mathrm{CO}^{*}\right)$ with $\mathrm{E}\left(\mathrm{OH}^{*}\right)$. A figure with full labeling of all points can be found in Figure S3

As shown in Figure 3, different $\mathrm{E}\left(\mathrm{CO}^{*}\right)-\mathrm{E}\left(\mathrm{OH}^{*}\right)$ scaling lines form for each group TMDs.

From linear fits ( $\mathrm{R}_{2}$ values in Table $\left.\mathrm{S} 2\right), \mathrm{E}\left(\mathrm{CO}^{*}\right)$ scale well with $\mathrm{E}\left(\mathrm{OH}^{*}\right)$ except on the $2 \mathrm{H}-\mathrm{VI}$ TMDs, which is probably why they do not scale well with $\mathrm{E}\left(\mathrm{COOH}^{*}\right)$ on $2 \mathrm{H}-\mathrm{VI}$ TMDs (Figure 2). Generally, $\mathrm{E}\left(\mathrm{OH}^{*}\right)$ do not scale with $\mathrm{E}\left(\mathrm{CO}^{*}\right)$ on $\mathrm{TM}$ surfaces26,27, but they may scale within 
the same class of material. For example, a good linear correlation has been found between $\mathrm{E}(\mathrm{O} *)$ and $\mathrm{E}\left(\mathrm{C}^{*}\right)$ on the Pd alloys28. Therefore, it is since the oxophilicity and carbophilicity of the TMDs vary with group and phase, the various groups and phases also show different $\mathrm{E}\left(\mathrm{COOH}^{*}\right)-\mathrm{E}\left(\mathrm{CO}^{*}\right)$ scaling relations. Along the same vein, scaling relations on the early transition metal carbides have also been found to depart from the transition metal surfaces because they show different oxophilicity/carbophicility from their parent transition metals29. The departure was rationalized with the adsorbate-surface valence configuration and the energy of the metal $s p$-states, rather than metal $d$-states that govern the scaling relation of pure transition metals.

From the scaling relations in Figure 2(b) and (c), several materials can be potential candidates for efficient $\mathrm{CO}_{2}$ reduction to $\mathrm{CO}$ and further $\mathrm{CO}$ reduction. From Figure 2(b), $\mathrm{PtS}_{2}$ and $\mathrm{PdSe} 2$ may be more active than $\mathrm{Au}(211)$ for $\mathrm{CO}_{2}$ reduction to $\mathrm{CO}$ because they have lower $\mathrm{E}\left(\mathrm{COOH}^{*}\right)$ than $\mathrm{Au}(211)$ but do not bind $\mathrm{CO}$. According to Figure 2(c), $\mathrm{PtSe} 2$, and $2 \mathrm{H}$ phase $\mathrm{Nb}$ and $\mathrm{Ta}$ dichalcogenides may have some potential to reduce $\mathrm{CO}$ further, since they bind $\mathrm{CO}$ stronger or similarly to $\mathrm{Cu}$ but with significantly reduced $\mathrm{CHO}^{*}$ energies. The transition state, however, must be evaluated since it does not necessarily scale with the binding energy of $\mathrm{CHO}^{*} 11$.

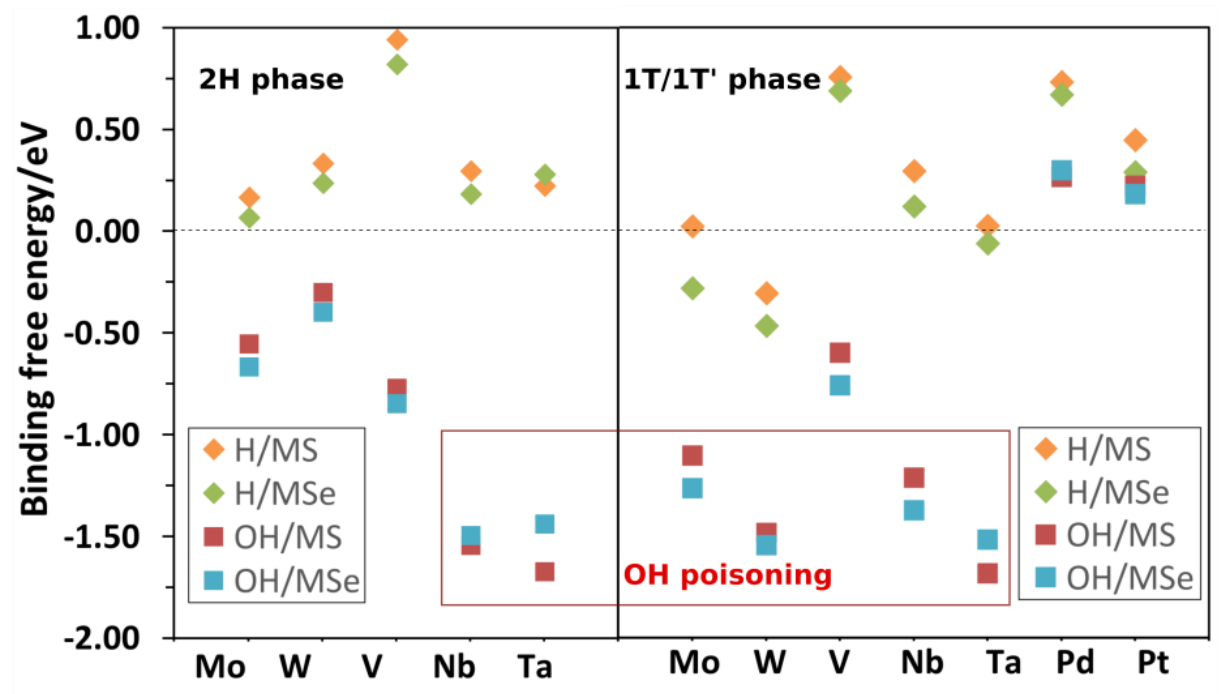

Figure 4, Binding free energies at the basal vacancy of the $2 \mathrm{H}$ and $1 \mathrm{~T} / 1 \mathrm{~T}$ ' phase TMDs 
To consider the competition with HER and the propensity for $\mathrm{OH}$ poisoning, we show the binding free energies of $\mathrm{H}^{*}$ and $\mathrm{OH}^{*}$ at $0.0 \mathrm{VRHE}$ in Figure 4 (structures in Figure 2). 2H-MoSe2, $1 \mathrm{~T}^{\prime}-\mathrm{MoS}_{2}, 1 \mathrm{~T}-\mathrm{NbSe}_{2}, 1 \mathrm{~T}-\mathrm{TaS}_{2}$ and 1T-TaSe2 are suggested to be efficient catalysts for HER since the $\Delta \mathrm{G}\left(\mathrm{H}^{*}\right)$ on them is close to thermoneutral30. On the other hand, $\Delta \mathrm{Go}\left(\mathrm{OH}^{*}\right)$ on $\mathrm{Nb}, \mathrm{Ta}$ dichalcogenides $(1 \mathrm{~T}$ and $2 \mathrm{H})$, Mo and $\mathrm{W} 1 \mathrm{~T}^{\prime}$-dichalcogenides are lower than $-1.0 \mathrm{eV}$, which suggests that they may suffer from $\mathrm{OH}$ poisoning down to reducing potentials of $-1 \mathrm{~V}$ vs. RHE (See Supporting Information). Therefore, among all the candidates, only the group X TMDs, and in particular the $\mathrm{PtS}_{2}$ and $\mathrm{PtSe}_{2}$, are suggested by the thermochemical analysis to have potential to be active and selective for $\mathrm{CO}_{2} \mathrm{R}$ and be resistant to $\mathrm{OH}$ poisoning.
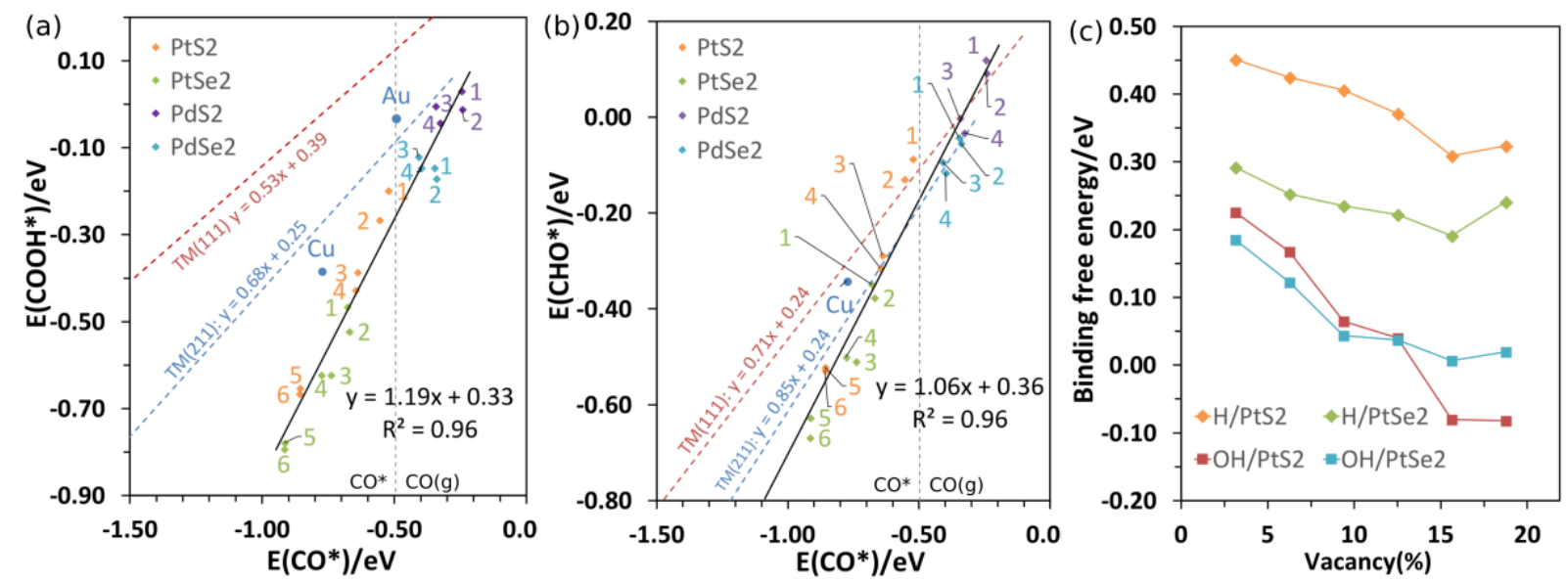

Figure 5(a) and (b): Scaling relations of group X TMDs with various densities of basal plane vacancies. The labels show the number of vacancies removed in $4 \times 4$ cells. (c), The change in the binding free energies of $\mathrm{H}$ and $\mathrm{OH}$ with the density of vacancies.

Finally, we investigate the effect of changing the density of basal vacancy on the scaling relations on group X TMDs. As shown in Figure 5, the binding of the intermediates change slightly with the density of vacancy on $\mathrm{PdS}_{2}$ and $\mathrm{PdSe}_{2}$, but change significantly on $\mathrm{PtS}_{2}$ and $\mathrm{PtSe}_{2}$ Therefore, $\mathrm{PdSe}_{2}$ remains a candidate for $\mathrm{CO}_{2} \mathrm{R}$ to $\mathrm{CO}$, whereas $\mathrm{PtS}_{2}$ at a high vacancy density and $\mathrm{PtSe}_{2}$ can bind $\mathrm{CO}$ and may be capable of reducing it further. Because $\mathrm{CO}^{*}$ is formed via $\mathrm{COOH}^{*}$, 
the thermodynamic limiting potential to form $\mathrm{CO}^{*}$ will decrease with increasing densities of vacancies; in addition, because the slope of the $\mathrm{E}\left(\mathrm{CHO}^{*}\right)-\mathrm{E}\left(\mathrm{CO}^{*}\right)$ scaling is larger than 1 (Figure 5(b)), the thermodynamic limiting potential to form $\mathrm{CHO}^{*}$ also decreases with increasing density26. Therefore, in the moderate $\mathrm{CO}$ binding regime, the activity of these materials is suggested to increase with the density of the vacancy. Since the slopes of the scaling relations are larger than those on $\operatorname{TM}(211)$ surfaces, and scaling lines lie below the $\mathrm{TM}(211)$ scaling lines, the present analysis suggests the vacancy on Pt dichalcogenides to be more active than the TM(211) surface, though the transition state should also be evaluated11. At the same time, the formation energies of $\mathrm{H}^{*}$ and $\mathrm{OH}^{*}$ are less sensitive to the density of the vacancy (Figure 5(c)), so the material should remain resistant to $\mathrm{HER}$ and $\mathrm{OH}$ poisoning. However, if the density of the vacancy becomes too high, the material would strongly bind $\mathrm{CO}$ and be poisoned by it, as in the case of strong binding metals for $\mathrm{CO}_{2} \mathrm{RR}$.

\section{Conclusions}

In summary, we have investigated the basal vacancies group $\mathrm{V}, \mathrm{VI}$ and $\mathrm{X}$ transition metal dichalcogenides in $2 \mathrm{H}$ and $1 \mathrm{~T} / 1 \mathrm{~T}$ ' phases for electrochemical reduction of $\mathrm{CO}_{2}$ by exploring the scaling relations of the key intermediates. Because of the difference in the oxygen affinity, the scaling relations deviate from transition metal ones and also show variations amongst TMDs of different groups and phases. Most of the TMDs were found to be either active for HER or prone to $\mathrm{OH}$ poisoning. Only group $\mathrm{X}$ TMDs are suggested to be active and selective candidates for $\mathrm{CO}_{2}$ reduction without suffering from $\mathrm{OH}$ poisoning. Furthermore, our calculations suggest that the performance can be improved and the selectivity and be tuned by increasing the density of basal 
vacancy. This work motivates further theoretical study including transition states and associated kinetics of the relevant intermediates and experimental testing of group X TMDs.

\section{Corresponding Author}

*kchan@ @ysik.dtu.dk

\section{Present Addresses}

$\dagger$ If an author's address is different than the one given in the affiliation line, this information may be included here.

\section{Funding Sources}

\section{Supporting Information}

Definition of $\mathrm{OH}$ poisoning effect; formation energy of S vacancies; adsorption structures of $\mathrm{OH}^{*}$ and $\mathrm{H}^{*}$; fully labeled figures and binding energies of all intermediates summarized in tables; parameters of the linearing fitting.

\section{Acknowledgment}

This work was supported by the U.S. Department of Energy, Office of Science, Office of Basic Energy Science, via Grant DE-SC0008685 to the SUNCAT Center of Interface Science and Catalysis, as well as the Villum Fonden through a research grant (9455). Y.J. thanks the Knut \& Alice Wallenberg Foundation for financial support through the Wallenberg Postdoctoral Scholarship Program.

\section{References}

(1) Asadi, M.; Kim, K.; Liu, C.; Addepalli, A. V.; Abbasi, P.; Yasaei, P.; Phillips, P.; Behranginia, A.; Cerrato, J. M.; Haasch, R.; et al. Nanostructured Transition Metal Dichalcogenide Electrocatalysts for $\mathrm{CO}_{2}$ Reduction in Ionic Liquid. Science 2016, 353, 467470.

(2) Asadi, M.; Kumar, B.; Behranginia, A.; Rosen, B. A.; Baskin, A.; Repnin, N.; Pisasale, D.; Phillips, P.; Zhu, W.; Haasch, R.; et al. Robust Carbon Dioxide Reduction on Molybdenum Disulphide Edges. Nat. Commun. 2014, 5, 4470. 
(3) Liu, X.; Yang, H.; He, J.; Liu, H.; Song, L.; Li, L.; Luo, J. Highly Active, Durable Ultrathin MoTe2 Layers for the Electroreduction of $\mathrm{CO}_{2}$ to $\mathrm{CH}_{4}$. Small 2018, 14, 1704049.

(4) Xu, J.; Li, X.; Liu, W.; Sun, Y.; Ju, Z.; Yao, T.; Wang, C.; Ju, H.; Zhu, J.; Wei, S.; et al. Carbon Dioxide Electroreduction into Syngas Boosted by a Partially Delocalized Charge in Molybdenum Sulfide Selenide Alloy Monolayers. Angew. Chem. 2017, 129, 9249-9253.

(5) Jaramillo, T. F.; Jørgensen, K. P.; Bonde, J.; Nielsen, J. H.; Horch, S.; Chorkendorff, I. Identification of Active Edge Sites for Electrochemical $\mathrm{H}_{2}$ Evolution from $\mathrm{MoS}_{2}$ Nanocatalysts. Science 2007, 317, 100-102.

(6) Abbasi, P.; Asadi, M.; Liu, C.; Sharifi-Ası, S.; Sayahpour, B.; Behranginia, A.; Zapol, P.; Shahbazian-Yassar, R.; Curtiss, L. A.; Salehi-Khojin, A. Tailoring the Edge Structure of Molybdenum Disulfide toward Electrocatalytic Reduction of Carbon Dioxide. ACS Nano 2017, 11, 453-460.

(7) Rosen, B. A.; Salehi-Khojin, A.; Thorson, M. R.; Zhu, W.; Whipple, D. T.; Kenis, P. J. A.; Masel, R. I. Ionic Liquid-Mediated Selective Conversion of $\mathrm{CO}_{2}$ to $\mathrm{CO}$ at Low Overpotentials. Science 2011, 334, 643-644.

(8) Chen, L. D.; Urushihara, M.; Chan, K.; Nørskov, J. K. Electric Field Effects in Electrochemical $\mathrm{CO}_{2}$ Reduction. ACS Catal. 2016, 6, 7133-7139.

(9) Wang, Y.; Hatakeyama, M.; Ogata, K.; Wakabayashi, M.; Jin, F.; Nakamura, S. Activation of $\mathrm{CO}_{2}$ by Ionic Liquid EMIM-BF4 in the Electrochemical System: A Theoretical Study. Phys. Chem. Chem. Phys. 2015, 17, 23521-23531.

(10) Feaster, J. T.; Jongerius, A. L.; Liu, X.; Urushihara, M.; Nitopi, S. A.; Hahn, C.; Chan, K.; Nørskov, J. K.; Jaramillo, T. F. Understanding the Influence of [EMIM]Cl on the Suppression of the Hydrogen Evolution Reaction on Transition Metal Electrodes. Langmuir 2017, 33, 9464-9471.

(11) Landers, A. T.; Fields, M.; Torelli, D. A.; Xiao, J.; Hellstern, T. R.; Francis, S. A.; Tsai, C.; Kibsgaard, J.; Lewis, N. S.; Chan, K.; et al. The Predominance of Hydrogen Evolution on Transition Metal Sulfides and Phosphides under $\mathrm{CO}_{2}$ Reduction Conditions: An Experimental and Theoretical Study. ACS Energy Lett. 2018, 3, 1450-1457.

(12) Tsai, C.; Li, H.; Park, S.; Park, J.; Han, H. S.; Nørskov, J. K.; Zheng, X.; Abild-Pedersen, F. Electrochemical Generation of Sulfur Vacancies in the Basal Plane of $\mathrm{MoS}_{2}$ for Hydrogen Evolution. Nat. Commun. 2017, 8, 15113.

(13) Li, H.; Tsai, C.; Koh, A. L.; Cai, L.; Contryman, A. W.; Fragapane, A. H.; Zhao, J.; Han, H. S.; Manoharan, H. C.; Abild-Pedersen, F.; et al. Activating and Optimizing MoS2 Basal Planes for Hydrogen Evolution through the Formation of Strained Sulphur Vacancies. Nat. Mater. 2016, 15, 48-53.

(14) Chan, K.; Tsai, C.; Hansen, H. A.; Norskov, J. K. Molybdenum Sulfides and Selenides as Possible Electrocatalysts for $\mathrm{CO}_{2}$ Reduction. Chemcatchem 2014, 6, 1899-1905.

(15) Hong, X.; Chan, K.; Tsai, C.; Nørskov, J. K. How Doped MoS2 Breaks Transition-Metal Scaling Relations for $\mathrm{CO}_{2}$ Electrochemical Reduction. ACS Catal. 2016, 6, 4428-4437.

(16) Giannozzi, P.; Baroni, S.; Bonini, N.; Calandra, M.; Car, R.; Cavazzoni, C.; Davide Ceresoli; Chiarotti, G. L.; Cococcioni, M.; Dabo, I.; et al. QUANTUM ESPRESSO: A Modular and Open-Source Software Project for Quantum Simulations of Materials. J. Phys. Condens. Matter 2009, 21, 395502.

(17) Kresse, G.; Furthmüller, J. Efficiency of Ab-Initio Total Energy Calculations for Metals and Semiconductors Using a Plane-Wave Basis Set. Comput. Mater. Sci. 1996, 6, 15-50. 
(18) Kresse, G.; Hafner, J. Norm-Conserving and Ultrasoft Pseudopotentials for First-Row and Transition Elements. J. Phys. Condens. Matter 1994, 6, 8245.

(19) Bahn, S. R.; Jacobsen, K. W. An Object-Oriented Scripting Interface to a Legacy Electronic Structure Code. Comput. Sci. Eng. 2002, 4, 56-66.

(20) Wellendorff, J.; Lundgaard, K. T.; Møgelhøj, A.; Petzold, V.; Landis, D. D.; Nørskov, J. K.; Bligaard, T.; Jacobsen, K. W. Density Functionals for Surface Science: ExchangeCorrelation Model Development with Bayesian Error Estimation. Phys. Rev. B 2012, 85, 235149.

(21) Bengtsson, L. Dipole Correction for Surface Supercell Calculations. Phys. Rev. B 1999, 59, 12301-12304.

(22) Nørskov, J. K.; Rossmeisl, J.; Logadottir, A.; Lindqvist, L.; Kitchin, J. R.; Bligaard, T.; Jónsson, H. Origin of the Overpotential for Oxygen Reduction at a Fuel-Cell Cathode. J. Phys. Chem. B 2004, 108, 17886-17892.

(23) Peterson, A. A.; Abild-Pedersen, F.; Studt, F.; Rossmeisl, J.; Nørskov, J. K. How Copper Catalyzes the Electroreduction of Carbon Dioxide into Hydrocarbon Fuels. Energy Environ. Sci. 2010, 3, 1311-1315.

(24) Duerloo, K.-A. N.; Li, Y.; Reed, E. J. Structural Phase Transitions in Two-Dimensional Moand W-Dichalcogenide Monolayers. Nat. Commun. 2014, 5, 4214.

(25) Tsai, C.; Chan, K.; Nørskov, J. K.; Abild-Pedersen, F. Theoretical Insights into the Hydrogen Evolution Activity of Layered Transition Metal Dichalcogenides. Surf. Sci. 2015, 640, 133140.

(26) Peterson, A. A.; Norskov, J. K. Activity Descriptors for $\mathrm{CO}_{2}$ Electroreduction to Methane on Transition-Metal Catalysts. J. Phys. Chem. Lett. 2012, 3, 251-258.

(27) Liu, X.; Xiao, J.; Peng, H.; Hong, X.; Chan, K.; Nørskov, J. K. Understanding Trends in Electrochemical Carbon Dioxide Reduction Rates. Nat. Commun. 2017, 8, ncomms 15438.

(28) Xin, H.; Vojvodic, A.; Voss, J.; Nørskov, J. K.; Abild-Pedersen, F. Effects of d -Band Shape on the Surface Reactivity of Transition-Metal Alloys. Phys. Rev. B 2014, 89, 115114.

(29) Michalsky, R.; Zhang, Y.-J.; Medford, A. J.; Peterson, A. A. Departures from the Adsorption Energy Scaling Relations for Metal Carbide Catalysts. J. Phys. Chem. C 2014, 118, 1302613034.

(30) Greeley, J.; Jaramillo, T. F.; Bonde, J.; Chorkendorff, I.; Nørskov, J. K. Computational HighThroughput Screening of Electrocatalytic Materials for Hydrogen Evolution. Nat. Mater. 2006, 5, 909-913. 


\section{TOC Graphic}

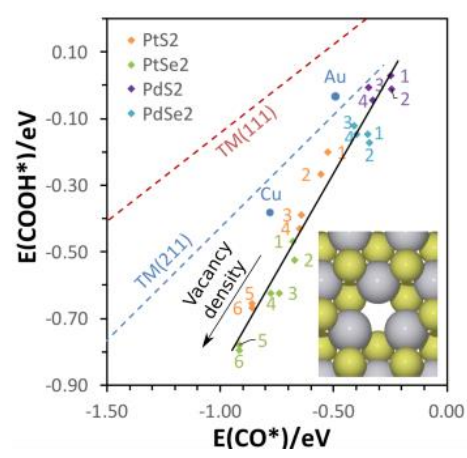

